\title{
SENTIDOS E SIGNIFICADOS DE SER MULHER, NEGRA, POBRE E ANALFABETA
}

\author{
Samira de Moraes Maia Vigano \\ Instituto Federal de Santa Catarina (IFSC), Brasil. \\ E-mail: samirammvigano@gmail.com \\ ORCID: https://orcid.org/0000-0001-8100-9207
}

Data de recebimento: 30/01/2020

Data de aprovação: 22/03/2020

DOI: https://doi.org/10.30612/frh.v22i39.12572

\begin{abstract}
Resumo: Trata-se de um artigo que busca trazer relatos das sujeitas mulheres da Educação de Jovens e Adultos (EJA), de uma turma de alfabetização. Os relatos foram coletados em 2019 e fazem parte dos registros das atividades da professora daquela turma. A EJA tem por característica a forte presença de mulheres, em especial, nessa turma, eram mulheres, negras, pobres e oriundas do Nordeste do Brasil. Os relatos trazidos contextualizam processos de discriminações e preconceitos, resultantes de uma cultura machista, sexista, racista e misógina. Utiliza-se como procedimento metodológico a análise do conteúdo, respaldando-se teoricamente em Arroyo (2003, 2005 e 2010), Louro (1997), Munanga (1988, 2004 e 2006), Scott (1995) e Poggio (2012). Incorporou-se ao debate os processos constituidores de identidades relacionados às questões de gênero, raça, etnia, classe social e escolarização, objetivando compreender as relações vivenciadas pelas sujeitas da EJA, pautadas nas falas interseccionadas de gênero, raça, etnia, classe social e escolarização. Tal debate tem o propósito de consolidar as vozes das mulheres da EJA.
\end{abstract}

Palavras-chave: Gênero. Raça. Mulheres. Escolarização.

\section{SENSES AND MEANINGS OF BEING A WOMAN, BLACK, POOR AND ILLITERATE}

\begin{abstract}
This is an article that seeks to bring reports from the subject women of Youth and Adult Education (EJA), from a literacy class. The reports were collected in 2019 and are part of the records of the activities of the teacher of that class. EJA is characterized by the strong presence of women, especially in this class, they were women, black, poor and from the Northeast of Brazil. The reports brought contextualize processes of discrimination and prejudice, resulting from a sexist, sexist, racist and misogynist culture. Content analysis is used as a methodological procedure, supported theoretically by Arroyo (2003, 2005 and 2010), Louro (1997), Munanga (1988, 2004 and 2006), Scott (1995) and Poggio (2012). The identity constituent processes related to issues of gender, race, ethnicity, social class and schooling were incorporated into the debate, aiming to understand the relationships experienced by the subjects of EJA, based on the intersecting speeches of gender, race, ethnicity, social class and schooling. Such a debate has the purpose of consolidating the voices of women from EJA.
\end{abstract}

Keywords: Gender. Breed. Women. Schooling. 


\section{SENTIDOS Y SIGNIFICADOS DE SER MUJER, NEGRA, POBRE Y ANALFABETA}

Resumen: Este es un artículo que busca traer informes del tema mujeres de Educación de Jóvenes y Adultos (EJA), de una clase de alfabetización. Los informes se recopilaron en 2019 y son parte de los registros de las actividades del maestro de esa clase. EJA se caracteriza por la fuerte presencia de mujeres, especialmente en este grupo, eran mujeres, negras, pobres y del Noreste de Brasil. Los informes trajeron procesos contextualizados de discriminación y prejuicio, resultantes de una cultura sexista, sexista, racista y misógina. El análisis de contenido se utiliza como un procedimiento metodológico, apoyado teóricamente por Arroyo (2003, 2005, 2010), Louro (1997), Munanga (1988, 2004, 2006), Scott (1995) y Poggio (2012). Los procesos constitutivos de identidad relacionados con cuestiones de género, raza, etnia, clase social y escolarización se incorporaron al debate, con el objetivo de comprender las relaciones experimentadas por los sujetos de EJA, en base a los discursos entrecruzados de género, raza, etnia, clase social y escolaridad. Tal debate tiene el propósito de consolidar las voces de las mujeres de EJA.

Palabras clave: Género. Raza. Mujer. Escolarización.

\section{Introdução}

Este artigo, intitulado Sentidos e significados de ser mulher, negra, pobre e analfabeta, apresenta como tema central o reconhecimento dos sentidos singulares na vida histórico-social de alunas da Educação de Jovens e Adultos (EJA). A Educação de Jovens e Adultos no Brasil é processo de escolarização voltado a jovens, adultos e idosos que não concluíram seu percurso escolar em outras fases da vida. Em geral, o público da EJA é da classe trabalhadora e estuda no período noturno, organizando-se entre sua vida pessoal, seu trabalho e os seus estudos. Consiste em um processo historicamente marcado por trajetórias ligadas às transformações ocorridas no mundo, sendo elas: sociais, econômicas ou políticas. A EJA é proveniente de um percurso gradativo de lutas dos movimentos sociais, que buscaram a igualdade e o direito constitucional de estudo. Consideram-se as vivências cheias de percalços, marcada por tensões entre diferentes projetos de sociedade e diferentes ideias sobre as finalidades da EJA, constituindo-se, muitas vezes, em uma educação de segundo plano.

Podemos compreender aqueles que participam dos processos de EJA como sujeitos socioculturais e, assim, percebê-los inseridos em um processo cultural e histórico de periodização da vida, constituído de semelhanças e particularidades. Dessa forma, o gênero, a raça, a sexualidade e a subjetividade serão entendidos como processos e dimensões integrantes da EJA, que se expressam na vida e nas relações estabelecidas entre os diversos sujeitos sociais que dela fazem parte (GOMES, 2005, p. 89). 
É importante trazer ao debate as relações existentes nesses espaços educativos, já que a EJA é sinalizada como um universo a parte, onde circulam pessoas que vivem a margem de direitos sociais. Assim, esse artigo busca contextualizar a EJA e seus educandos, e é baseado em relatos das sujeitas mulheres da EJA, de uma turma de alfabetização noturna. Os relatos foram coletados no decorrer do ano de 2019 no município de Florianópolis, capital do estado de Santa Catarina, em uma escola da rede municipal de educação, pela professora alfabetizadora da turma. A turma era composta por 18 estudantes, sendo 11 mulheres, negras, pobres, idosas, moradoras de comunidades da região norte do município. É importante destacar que as alunas dessa turma da EJA eram, em maioria, provenientes de estados do Nordeste do país e tinham entre 50 e 75 anos.

Ressalta-se a forte presença de mulheres nas turmas da EJA, caracterizando o processo de escolarização como um território em que as educandas fazem parte e fortalecem as suas relações sociais. É sabido que as mulheres, em geral, e essas alunas especialmente, se constituíram por meio de discriminações e preconceitos, resultantes de uma cultura machista, sexista, racista e misógina. Entretanto, é notório que as mulheres buscaram através dos movimentos sociais, o fortalecimento e a luta pela igualdade de direitos, ocupando cada vez mais os espaços educativos, o que evidenciou uma maior presença feminina nas salas de aula das EJAs no Brasil.

A Pesquisa Nacional por Amostra de Domicílios (PNAD) demonstrou que, no ano de 2007, a EJA era composta por 54\% de alunas mulheres (IBGE, 2007). Ou seja, a perspectiva de gênero se evidenciou nas classes da EJA, naquele período de acordo com os dados censitários. Isso ocorre, porque, a construção escolar na sociedade ocidental organizouse de forma a separar e excluir as mulheres, e muitas, só obtiveram oportunidade de estudo, quando adultas ou idosas. Em relação à alfabetização, a análise dos resultados do censo demográfico publicado em 2014 (IBGE, 2010) anunciou que a maioria das pessoas analfabetas são mulheres com 60 anos ou mais. No grupo etário 60 anos ou mais, a taxa de analfabetismo das pessoas de cor branca alcança $10,3 \%$ e, entre as pessoas pretas ou pardas o percentual é de $27,5 \%$, e as regiões Nordeste e Norte apresentaram uma taxa de analfabetismo maior do que as regiões do Centro-Sul do país (IBGE, 2010).

Segundo Arroyo (2010) “os estudos, as pesquisas e os debates sobre a relação entre educação e desigualdades têm sido um dos campos mais fecundos e instigantes no pensamento educacional progressista e na formulação e gestão, na análise e avaliação de políticas educativas" (ARROYO, 2010, p. 1382). Sendo assim "as políticas e projetos são pensados como solução, como oportunidades oferecidas; como pontes, ao menos como ISSN: $2175-0742$ | v. 22 | n. 39 | p. 107-123 | Jan. / Jun. 2020 
passarelas ou pinguelas para esses percursos de passagem. Ao estado e suas instituições cabe oferecer essas pontes e passarelas" (ARROYO, 2010, p. 1390), já que, uma ação contínua de fortalecimento das relações de igualdade de direitos, não é realizada.

A EJA é uma modalidade de ensino da educação básica, que objetiva a elevação de escolaridade de sujeitos jovens e adultos, que não concluíram o ensino fundamental e/ou o ensino médio enquanto crianças ou adolescentes. Infelizmente, sabe-se que "desde que a EJA é EJA, os jovens e adultos são os mesmos: pobres, desempregados, vivem da economia informal, negros, vivem nos limites da sobrevivência" (ARROYO, 2005, p. 29). É primordial reconhecer os sujeitos da EJA como pessoas que trazem demandas específicas, muitas vezes, relacionadas com vivências em contexto empobrecidos, provenientes de violências, compreendendo que se trata de uma modalidade de ensino que deve fortalecer a cultura e os saberes prévios dos sujeitos envolvidos.

Em uma turma de alfabetização da EJA há uma forte busca pela leitura e pela escrita, todavia, quando essa turma é composta por uma maioria de mulheres idosas, há a busca por reconhecimento e por ser ouvida, isso porque, elas passaram muitos anos das suas vidas sem poder dar voz as suas angústias. Nesse viés, ao trazer as falas e dialogar com as questões relacionadas com gênero, raça, etnia, classe social e o processo de escolarização dessas sujeitas, demonstra-se a face das alunas e as dificuldades existentes em relação a esses marcadores. Esclarece-se que as falas surgiram de forma esporádica no decorrer das atividades letivas, e foram anotadas no caderno da professora e utilizadas em vários momentos na sua prática pedagógica na busca de desconstruir estereótipos e fortalecer a relação - professora e alunas. Os registros realizados pela docente serviram como mediadores de algumas ações alfabetizadoras, como por exemplo, a leitura do livro Quarto de despejo: diário de uma favelada da autora Carolina Maria de Jesus. A escolha de tal livro pela professora veio do fato de que a autora da obra é uma mulher, negra, pobre e pouco escolarizada. A leitura de partes do livro era esperada com ansiedade pelas alunas todos os dias.

Indica-se que, no transcorrer do texto, utilizam-se procedimentos metodológicos que dialogam e analisam as falas das sujeitas, relacionando-as às categorias de gênero, raça, escolarização e etnia, buscando assim, estabelecer um projeto descritivo e categorizado, contemplando como recurso primordial, a análise de conteúdo (BARDIN, 2009). A análise de conteúdo consiste em explicitar claramente os objetivos, e ajuda a delimitar os dados efetivamente significativos (BARDIN, 2009). Justifica-se tal escolha por perceber que "as manifestações do comportamento humano, a expressão verbal, seus enunciados e suas 
mensagens passam a ser vistos como indicadores indispensáveis para a compreensão dos problemas ligados às práticas educativas e seus componentes psicossociais". (FRANCO, 2008, p. 08).

Muito embora se precise, cada vez mais, ampliar as investigações que se debrucem sobre esses temas, é preciso salientar a importância e necessidade de debates como esse, mesmo porque, se não existir o debate, será difícil acabar com o preconceito e com a discriminação, já que "não existem leis no mundo que sejam capazes de erradicar as atitudes preconceituosas existentes nas cabeças das pessoas, atitudes essas provenientes dos sistemas culturais de todas as sociedades humanas”. (MUNANGA, 2005, p. 17). Tal perspectiva admite que:

[...] as palavras têm história, ou melhor, que elas fazem história, o conceito de gênero que pretendo enfatizar está ligado diretamente à história do movimento feminista contemporâneo. Constituinte desse movimento, ele está implicado linguística e politicamente em suas lutas e, para melhor compreender o momento e o significado de sua incorporação, é preciso que se recupere um pouco de todo o processo (LOURO, 1997, p. 14).

Apresentar-se-á no decorrer da escrita, as questões de gênero, raça, etnia e escolarização relacionada às alunas, discorrendo teoricamente sobre essas temáticas, os marcadores de gênero e as violências. O objetivo do texto é de compreender as relações vivenciadas pelas sujeitas da EJA, pautadas nas falas interseccionadas de gênero, raça, etnia, classe social e escolarização. Tal debate tem o propósito de consolidar as vozes das mulheres da EJA. "Coloca-se aqui, no meu entender, uma das mais significativas marcas dos Estudos Feministas: seu caráter político". (LOURO, 1997, p. 19). Para tanto, incorpora-se como base teórica: Arroyo (2003; 2005; 2010), Louro (1997), Munanga (1988; 2004; 2005), Scott (1995) e Poggio (2012). A combinação das abordagens: teórica e empírica, objetiva contribuir na composição de uma investigação educacional mais crítica e atual, demonstrando que pode ser significativas ambas às interfaces, e que juntas, podem dimensionar melhor a problemática exposta.

\section{Sentidos e significados interseccionados}


As questões de gênero se interseccionam com demais processos de violências vivenciados pelas alunas da EJA, principalmente aspectos de raça e etnia. As questões de gênero pressupõem pensar no feminino e no masculino como construções sociais baseadas nos corpos biológicos. Muito embora se reconheça que gênero vai além do biológico, é necessário compreender como essas relações se solidificam, a ponto de evidenciar uma superioridade do homem em relação à mulher. Em linhas gerais, Scott (1995) retrata que, gênero é uma categoria importante para pensar as relações sociais históricas, que envolvem homens e mulheres, relações determinadas e expressadas pelos diferentes discursos que se projetam a partir da diferença biológica. De acordo com essa autora, gênero é uma categoria historicamente construída, a qual, não dimensiona apenas sobre a diferença entre os sexos, mas, sobretudo, se constitui como uma categoria que dá sentido a essa diferença biológica, seus marcadores e papéis. "Papéis seriam, basicamente, padrões ou regras arbitrárias que uma sociedade estabelece para seus membros e que definem seus comportamentos, suas roupas, seus modos de se relacionar ou de se portar" (LOURO, 1997, p. 24).

O termo gênero é uma maneira de indicar construções culturais, orientadas por uma hierarquização dos sexos e se constitui em uma criação inteiramente social de ideias sobre papéis situados aos homens e às mulheres. Trata-se de uma forma de se referir às origens exclusivamente sociais das identidades subjetivas dos sujeitos e, consequentemente, gênero é, segundo esse entendimento, uma categoria social imposta sobre um corpo sexuado (SCOTT, 1995).

Homens e mulheres certamente não são construídos apenas através de mecanismos de repressão ou censura, eles e elas se fazem, também, através de práticas e relações que instituem gestos, modos de ser e de estar no mundo, formas de falar e de agir, condutas e posturas apropriadas (e, usualmente, diversas). Os gêneros se produzem, portanto, nas e pelas relações de poder (LOURO, 1997, p. 41).

A igualdade reside no que é diferente e no discurso da diferença entre machos e fêmeas, e ainda, na ocultação das inúmeras diferenças entre as mulheres quanto à origem de classes, raças, etnias, culturas, gerações, comportamentos, caracteres, desejos, subjetividades, sexualidades e experiências históricas (SCOTT, 1995). A compreensão de uma diferença múltipla ao invés da diferença binária. Assim, entende-se gênero como uma construção cultural e sexo como biológico, mas que pode ser constituído dentro das relações sociais e culturais (SCOTT, 1995). "Os desdobramentos e debates teóricos, no entanto, permitiram pensar que o próprio binarismo sexual é uma produção cultural e o corpo deixa de ser uma constante para ser visto como uma variável” (TONELI, 2012, p. 149). Nesse sentido, “essas 
proposições permitem pensar a sexualidade como construções sociais e históricas que sempre implicam certo tipo de conexão com as relações de poder" (TONELI, 2012, p. 151). Desse modo, ao "rejeitar um determinismo biológico implícito no uso de termos como sexo ou diferença sexual", enfatiza-se o "caráter fundamentalmente social das distinções baseadas no sexo" (SCOTT, 1995, p. 72).

É imperativo, então, contrapor-se a esse tipo de argumentação. É necessário demonstrar que não são propriamente as características sexuais, mas é a forma como essas características são representadas ou valorizadas, aquilo que se diz ou se pensa sobre elas que vai constituir, efetivamente, o que é feminino ou masculino em uma dada sociedade e em um dado momento histórico. Para que se compreenda o lugar e as relações de homens e mulheres numa sociedade importa observar não exatamente seus sexos, mas sim tudo o que socialmente se construiu sobre os sexos. O debate vai se constituir, então, através de uma nova linguagem, na qual gênero será um conceito fundamental (LOURO, 1997, p. 21).

Com relação à raça, esse é um conceito biológico, ou seja, por critérios genéticos de fato somos iguais enquanto seres humanos. Porém, por questões sociais não somos iguais, sendo diferenciados hierarquicamente (MUNANGA, 2004). Há uma desvalorização da pessoa negra, já que a denominação da cor branca foi se intensificando nos países ocidentais, pois em geral, ocorre uma valorização positiva do ser "branco", e uma desvalorização da cor negra (PETRUCCELLI, 2000).

Ao juntar essas duas características nas alunas da EJA - ser negra e ser mulher, ocorre, consequentemente, a interseccionalidade, ou seja, uma junção de fatores que geram agentes discriminatórios. Essa intersecção de fatores origina-se da sobreposição de ações relacionadas à opressão ou discriminação, vinculadas a diferentes categorias biológicas, sociais ou culturais. A interseccionalidade compreende que as opressões e discriminações não agem independentes, elas se conectam, criando um sistema cada vez mais excludente.

Ao capturar as consequências estruturais e dinâmicas da interação entre dois ou mais eixos da subordinação. Ela trata especificamente da forma pela qual o racismo, o patriarcalismo, a opressão de classe e outros sistemas discriminatórios criam desigualdades básicas que estruturam as posições relativas de mulheres, raças, etnias, classes e outras (CRENSHAW, 2002, p. 177).

Aspectos referentes à raça e cor tornam-se propulsores das discriminações, juntamente com as questões de gênero e escolaridade, e demonstram que a promoção da igualdade universalizada pelos Direitos Humanos não se dá da mesma forma para todos e todas, visto que, "a história presente expõe as marcas do racismo institucionalizado". (PASSOS, 2012, p. 136). Nesse sentido, as demandas referentes às relações entre homens e 
mulheres e as desigualdades existentes entre gênero, raça e etnia, conduzem há algo que está cada vez mais em pauta no contexto atual e que aflora em uma cultura que prioriza as pessoas brancas, heterossexuais, cristãs, de uma classe social abastada e de preferência que sejam homens. Essas questões sugerem um cuidadoso olhar a respeito do debate de igualdade, de marcadores sociais e direitos que foram dissimulados pelos discursos hegemônicos (POGGIO, 2012). Em se tratando de gênero e suas intersecções Butler (2013) afirma que:

[...] nem sempre se constituiu de maneira coerente ou consistente nos diferentes contextos históricos, e porque o gênero estabelece intersecções com as modalidades raciais, classistas, étnicas, sexuais e regionais de identidades discursivamente constituídas. Resultado que se tornou impossível separar a noção de "gênero" as intersecções políticas e culturais em que invariavelmente ela é produzida e mantida (BUTLER, 2013, p. 21).

As alunas da EJA trazem relatos pautados nas imposições delimitadas para cada sexo, dentro de uma cultura patriarcal, a qual, os estereótipos são historicamente produzidos, buscando a segregação de mulheres. Há de se ter noção de que, geralmente, as alunas de uma turma de alfabetização da EJA são pessoas idosas e provenientes de contextos empobrecidos. Contribui na discussão sobre as falas das sujeitas, a memória que elas trazem das vivências sociais. Pensar na memória como refletida, guiada por um processo de reflexão do passado, expressada no presente. É como se o conhecimento histórico não fosse algo fiel a realidade vivida, logo, essa memória se embaraça com as condições vivenciadas por essas mulheres ao longo do tempo, e oferece uma nova compreensão das vivências, as quais, o gênero e raça são produzidos e constituídos nas identidades das sujeitas.

Era comum ouvir um relato triste e cheio de mágoa das alunas. Todas as aulas, em que era feita a leitura do livro da Carolina Maria de Jesus, surgiam falas pessoais e muito próximas ao contexto vivido por Carolina. Carolina, por sua vez, foi uma mulher pobre, catadora de lixo e negra, estudou apenas até o segundo ano do ensino fundamental, no entanto, sempre foi uma leitora árdua, o que fez com que, sua escrita fluísse. O livro Quarto de despejo: diário de uma favelada é um diário escrito na década de 1950, em que, ela conta o seu dia a dia na favela do Canindé no Rio de Janeiro. Certa vez, um repórter que estava pela favela, efetuando uma matéria para um jornal local, ficou curioso e solicitou vistas as escrituras de Carolina. Surpreendido com tamanha contextualização histórica da vida de uma mulher negra, pobre e favelada, ele propôs a ela a publicação do diário em forma de livro. Carolina ficou conhecida no mundo todo, foi uma das escritoras brasileiras mais vendidas, porém, nunca obteve a fama merecida, talvez pelo fato de ser mulher negra e pobre. De todo modo, ao trazer para as aulas a leitura do livro, a professora conseguiu com que as estudantes 
fizessem relatos semelhantes e se identificassem com a autora, proporcionando as estudantes um lugar de fala. Em várias partes do livro, Carolina contou que passou fome, que o pai não deixou que ela estudasse e que sofreu violência de alguns homens. Carolina escreveu: "levantei nervosa. Com vontade de morrer. Já que os pobres estão mal colocados, para que viver? Será que os pobres de outro país sofrem igual aos pobres do Brasil?” (JESUS, 2014, p. 33). Tais relatos coadunam com as falas das estudantes.

Eu nunca fui para a escola. Tinha 10 irmãos, só eu de mulher, e não pude estudar. Meu pai sempre dizia que estudar não era coisa para mulher direita, que as mulheres tinham que saber fazer os afazeres domésticos, era isso que importava (A. 68 anos, baiana).

Fui para escola muito pouco. Lembro que morava longe e era difícil. Tinha que dar conta dos trabalhos na roça e em casa. Vivia cansada e sem vontade. Apanhava muito dos meus irmãos e do meu pai (M. 60 anos, pernambucana).

Nunca fui à escola, quanta tristeza que sinto ao pensar que toda vez que falava em ir à escola, eu apanhava. Assim que pude, sumi de casa e nunca mais voltei, não tive notícias de ninguém mais da família. Logo me casei, e meu marido, também nunca me deixou estudar. Agora que sou viúva, vou aprender a ler. Tenho vergonha de pedir para verem o ônibus para mim $(\mathrm{N}$. 72 anos, paraibana).

Fui à escola até o quarto ano, depois, minha mãe disse que não era mais necessário, e eu achei mesmo que não era. Nunca li muito e nem escrevi, e por isso, não sei nada, até sei fazer contas, pois trabalhei com meu marido na mercearia dele e eu ficava no caixa, mas preciso muito aprender para ajudar minhas netas, eu cuido delas agora (M.S. 66 anos, pernambucana).

Fiz todas as minhas filhas estudarem, não vou fazer igual aos meus pais que só deixaram os meninos estudar. Elas estão até na faculdade, vou ser mãe de doutora (A. 68 anos, baiana).

Parei de estudar para cuidar dos meus irmãos, eles todos estudaram, somente eu que não pude. Mulher não tem inteligência para ficar perdendo tempo na escola. Não tinha inteligência para estudar, mas podia ficar o dia todo na roça ou na cozinha. Quando casei foi a mesma coisa. Agora que as minhas filhas obrigaram o pai a me deixar vir para a escola. Ele fica resmungando, mas obedece a elas (L. 73 anos, paranaense).

Passei muita fome na vida, e nunca pensei que fosse estudar alguma vez. $\mathrm{Na}$ nossa casa, a prioridade era a comida, a escola era longe e o caminho era perigoso para as meninas irem. Meus irmãos estudaram, eu e minhas irmãs nunca fomos para a escola (N. 72 anos, paraibana).

Percebe-se que muitas das alunas nunca foram para a escola quando eram crianças ou adolescentes. Relatam que foram impedidas de estudar porque eram mulheres. É interessante verificar que as marcas da privação lhes impediram por vários anos de estudar, 
todavia, assim que surgiu uma possibilidade de retorno, elas voltaram e se matricularam na EJA. Muitas iam para a escola com mochilas, com cadernos coloridos e infantilizados, tinham estojos com lápis de cores e eram frequentes nas aulas, mesmo tendo um dia todo de trabalho. Era forte o desejo por viver uma escola como se fosse a mesma de quando eram crianças, voltar no tempo, pertencer a uma história que lhes foi retirada.

Todas as alunas trabalhavam, umas com limpeza, outras na cozinha, ou como cuidadoras. Havia uma que era chefe de cozinha de um hotel grande e famoso da região, o que causou surpresa na professora, pois como ela conseguia fazer as receitas sem saber ler? Certa vez ela relatou que não seguia muito as receitas e que ninguém sabia que ela não era alfabetizada, pois ela criava algumas estratégias para que os colegas a ajudassem. Dizia que estava sem os óculos, que a letra era pequena, que tinha dor de cabeça, e assim por diante. Sabia que se fosse descoberta poderia perder o emprego ou sofrer preconceitos. O analfabetismo das alunas une-se aos demais fatores de exclusão. Ser analfabeta em uma sociedade letrada, onde tudo é escrito, torna-se um dificultador na vida das estudantes.

\begin{abstract}
Ah professora, estou vindo para a escola porque as minhas filhas insistem muito, mas eu sou muito burra para aprender, não vou conseguir nunca, estou velha, a cabeça não dá mais para essas coisas (L. 73 anos, paranaense).

Tenho uma vergonha de ir pegar o ônibus, sempre tenho que pedir para alguém olhar o nome para mim, mas digo que esqueci os óculos, depois vão ficar rindo de mim que sou uma analfabeta (J. 63 anos, baiana).
\end{abstract}

Em geral, as alunas da EJA voltam a estudar por várias questões, entre elas: ler a bíblia, trabalhar, pegar um ônibus, ler uma receita e ajudar nas tarefas dos netos ou netas. Questões simples do dia a dia, que se interseccionam aos demais fatores da exclusão.

O condicionamento e a naturalização do papel feminino, como apenas gerador do trabalho doméstico, se inter-relacionaram com a não necessidade de escolarização. "Exclusivamente dona de casa, guardiã do lar. E as próprias mulheres, em sua imensa maioria, têm de si próprias uma imagem cujo componente básico é um destino social profundamente determinado pelo sexo" (SAFFIOTI, 2013, p. 57). Trata-se de uma cultura que foi disseminada fortemente, pois a "serventia" da mulher é apenas casar e cuidar da casa. Atenta-se ao processo educativo como formador de uma consciência crítica, a escola, muito mais que ensinar conteúdos curriculares, dimensiona saberes e proporciona novos olhares as educandas, fazendo que consigam compreender seus direitos e interagir politicamente, tendo condições de transformar a sua realidade. Retirar o direito a escolarização, somente porque é 
uma mulher, trata-se de uma falácia, pois na verdade, retiram o seu direito pelo fato de que, o processo de escolarização emancipa e leva as sujeitas a se posicionarem criticamente diante das adversidades vividas. Não foi à toa que a escola foi negada as mulheres por muitos anos. Os homens sabem muito bem delimitar os espaços e orquestrar formas de dominação.

[...] a sociedade delimita, com bastante precisão, os campos em que pode operar a mulher, da mesma forma como escolhe os terrenos em que pode atuar o homem. A socialização dos filhos, por exemplo, constitui tarefa tradicionalmente atribuída às mulheres. Mesmo quando a mulher desempenha uma função remunerada fora do lar, continua a ser responsabilizada pela tarefa de preparar as gerações mais jovens para a vida adulta. A sociedade permite à mulher que delegue esta função a outra pessoa da família ou a outrem expressamente assalariado para este fim. Todavia, esta "permissão" só se legitima verdadeiramente quando a mulher precisa ganhar seu próprio sustento e o dos filhos ou ainda complementar o salário do marido (SAFFIOTI, 1987, p. 08).

Compreende-se que, desde a infância os estereótipos alinham-se conforme o que culturalmente é determinado para o ser feminino. "A sujeição de gênero, as desiguais relações de trabalho entre homens e mulheres se traduzem, não apenas na divisão e distribuição de tarefas, mas, sobretudo, nos critérios que deliberam a hierarquia e importância das funções" (POGGIO, 2012, p. 94). Essa cultura impregna-se de todos os lados, seja por intermédio das mídias, da família ou da literatura, pois a história revela que o patriarcado atravessa a sociedade como um todo (SAFFIOTI, 2013).

Em outro momento, ao fazer a leitura de um trecho do livro, a professora abriu um debate sobre as violências de gênero e relatou um pouco da história do movimento feminista e das lutas pelos direitos sociais. Muito interessadas no debate, às alunas logo incorporaram as suas falas ao contexto da sala de aula.

Eu apanhei muito do meu pai, apanhava por tudo, apanhava porque fazia comida muito boa e gastava muitos ingredientes, apanhava porque fazia a comida ruim, apanhava porque um homem me olhava na rua, era horrível, e pior, quando casei ficou tudo igual (S. 58 anos, baiana).

Eu fui estuprada várias vezes durante minha vida, sempre que ia ao campo buscar alguma coisa, havia um homem que me violentava. Eu tinha uns 12 anos, e isso ocorreu várias vezes. Certa vez, tentei contar ao meu pai e vi que ele ia me culpar pelo ocorrido e que iria me bater, não falei mais, continuei a minha vida, sendo estuprada quase que diariamente, já achava até normal (A. 68 anos, baiana).

Sabe essas marcas aqui professora, são de todas as vezes que meu pai me queimou com o cigarro. Tenho isso pelo corpo todo, lembro de cada uma, nem sei por que ele fazia isso, mas fazia sempre (M. 60 anos, pernambucana). 
Minha mãe era um monstro comigo, me bateu muito, meu pai era um pouco melhor, mas não era bom, mas não me batia. Quando pude sair de casa, saí para nunca mais voltar. Minha mãe ainda é viva, mas não quero nem saber dessa pessoa (P. 50 anos, cearense).

É necessário atentar-se às diversas manifestações da violência física, que são embasadas no abuso do poder e fundamentadas no que ou em quem se legitima como autoridade. "Do exposto, pode-se facilmente concluir que ambos - pai e mãe - contribuem para a perpetuação do poder masculino e adulto" (SAFFIOTI, 1987, p. 39). Avista-se que, enquanto as relações forem reguladas dentro de um sistema que privilegia um sexo em detrimento de outro, sempre terá quem domina e quem é dominado, pois se versa sob um sistema que hierarquiza as pessoas, fazendo com que os homens - principalmente os pais, irmãos e maridos, sejam superiores as mulheres. "Enquanto a identidade masculina se define em torno do trabalho produtivo e da luta por reconhecimento social, a identidade feminina ainda que a mulher deva trabalhar — se define pelo reconhecimento doméstico". (VALLE, 2002, p. 213). Para as mulheres excluídas da escola, restavam os afazeres domésticos, a maternidade, o cuidado dos filhos e filhas, o trabalho servil na roça, a violência sexual e a desqualificação pela falta de saberes.

Essa desigualdade de gênero é um problema de dominação, e a dominação se dá a partir da incorporação da ideologia dominante, seja na distribuição dos afazeres domésticos, na cultura, no trabalho, na escolarização e nas questões biológicas. As mulheres são vistas como frágeis e com um potencial intelectual inferior. "As sociedades instituem uma espécie de "definição" de funções para homens e mulheres, quase sempre pautadas em critérios sexistas, classistas e racistas, que, permanecem inquestionáveis e pouco alteradas no tempo" (POGGIO, 2012, p. 92). Em suma, os marcadores são constructos sociais caracterizados pelo gênero, pelos estereótipos e pelos papéis sociais que contribuem para a construção de preconceitos.

As violências são provenientes de vários espaços, e para essas alunas da EJA, elas se evidenciaram por questões de gênero e de raça. "Os conceitos de negro e de branco têm um fundamento étnico-semântico, político e ideológico, mas não um conteúdo biológico. [...] Trata-se de uma decisão política”. (MUNANGA, 2004, p. 52).

Ser negra foi um obstáculo para o acesso em alguns locais, elas relatam que se sentiram discriminadas e foram vítimas de racismo e preconceito. "A minha vida tem sido preta. Preta é minha pele. Preto é o lugar onde eu moro”. (JESUS, 2014, p. 167). 
Sempre que eu ia trabalhar, o porteiro fazia questão de me dizer que eu tinha que usar o elevador de serviço. Uma vez vi outra moça que limpava, entrando no elevador geral, e perguntei para o porteiro porque ela podia e eu não, e ele disse que os condóminos não iriam se sentir bem comigo no mesmo espaço, porque eu era negra (S. 58 anos, baiana).

Sabe professora, o meu maior sonho é ir para Disney, mas eu já fui três vezes, mas nunca consegui conhecer nada. Sempre ia para cuidar dos filhos da minha patroa, e quando chegava lá, ela me trancava no quarto do hotel, eu não podia descer nem para tomar café. Ficava o dia todo presa com um dos bebês, comendo o que ela levava. Nem quando eu saía do hotel para o aeroporto, ela me deixava olhar para rua, colocava um pano e eu não via nada (A. 68 anos, baiana).

Sou a responsável pela cozinha do hotel, mas nunca posso descer para servir ou ver os hóspedes, somente às outras cozinheiras brancas que podem (M. 60 anos, pernambucana).

Credo que mundo esse que a gente vive, eu vinha vindo para a escola e uma mulher ficou me olhando como se eu fosse uma doente, só porque sou negra e estou desarrumada, hoje saí do trabalho correndo, nem consegui passar em casa para tomar um banho, tu não te importas, né professora? (J. 63 anos, baiana).

Quando me casei com o meu primeiro marido, ele começou a me bater. Dizia que mulher tinha que apanhar às vezes para saber o seu lugar, eu até aceitava, pois sempre apanhei mesmo. Mas teve uma vez que ele disse que não era para eu engravidar nunca, fiquei bem triste, tinha o sonho de ser mãe. Certa vez ele deixou escapar que não queria ter filho comigo porque não queria filho preto, fiquei com tanta raiva que dessa vez eu que bati nele (P. 50 anos, cearense).

A violência é velada e naturalizada historicamente nas relações sociais. A “dominação e exploração de homens sobre as mulheres, de povos brancos sobre diversas etnias, assim como de ricos sobre pobres, tem sido um importante mecanismo de manutenção do status quo, reforçando preconceitos e estereótipos [...]” (POGGIO, 2012, p. 92). É perceptível que as situações relatadas pelas estudantes demonstram que o preconceito faz parte de suas vidas. Embora elas saibam claramente isso, elas não se posicionam frente a essas violências, isso porque, há no imaginário de cada uma, a ideia de inferioridade, seja pela questão da cor, como pela pobreza e pela falta de escolaridade. "Pelas diferenças biológicas entre povos negros e brancos, tentou-se explicar as culturas e concluir-se por uma diminuição intelectual e moral dos primeiros” (MUNANGA, 1988, p. 6). As reações de quem sofre preconceito, discriminação e violência sexual são diferentes; tem pessoas que reagem com indiferença, mesmo sendo afetadas, elas incorporam e naturalizam essas situações como se nada pudessem fazer a respeito, todavia, nem sempre conseguem restaurar sua autoestima e fortalecer seus objetivos de vida. Outras pessoas tendem a entrar em depressão ou em uma 
tristeza profunda, obstaculizando o seu convívio em sociedade, sentindo-se inferiores, como apareceu em alguns relatos. As situações vivenciadas e relatadas pelas estudantes demonstraram que suas memórias ainda são repletas de processos negativos e que a busca por um melhor entendimento de sua realidade está, também, em sua participação nos espaços da escola.

\section{Considerações finais}

A caminhada dos movimentos feministas obteve transformações sociais, sobretudo no campo dos direitos das mulheres, repercutindo mudanças em todas as dimensões sociais. Entretanto, apesar das conquistas feministas, ainda perduram assimetrias de gênero. Os conflitos originados nas questões relativas a gênero e raça, se atravessam nos relatos das estudantes, juntamente com as questões da pobreza e do analfabetismo. A interseccionalidade apresentada compreendeu que as opressões e discriminações não agem independentes, elas acabam por se conectar, criando um sistema cada vez mais excludente. Quando se estabelecem as distinções entre o gênero e raça, e quando se padroniza papéis sociais por meio de marcadores, acaba-se projetando preconceitos e desigualdades. Ao entender que essas sujeitas buscaram a escola para poder receber mais autonomia nas questões de letramento, entende-se, também, que a escola tem um papel fundamental para quebrar com esses preconceitos relatados pelas estudantes, em busca da socialização e de amplificação de uma cultura que valorize a diversidade.

As alunas da EJA, em geral, carregam marcas de processos excludentes vivenciados em vários espaços. Essas exclusões fizeram com que a escola não fizesse parte da vida de muitas dessas educandas, elas carregam características singulares, culturas diversas e marcas de violências sofridas no decorrer de suas vidas em relação ao seu gênero, sua raça, etnia, escolarização e classe social. Por conseguinte, ao deixar que as alunas relatassem suas vidas, a professora atuou dentro de uma prática que se materializa no concreto. Assim, é necessário que a EJA seja "modalidade de educação para sujeitos concretos, em contextos concretos, com histórias concretas, com configurações concretas. Sendo que qualquer tentativa de diluílos em categorias muito amplas os desfigura" (ARROYO, 2005, p. 02), tendo em vista que vive-se em um movimento de reconhecimento e valorização dos sujeitos da EJA, enquanto suas particularidades e pluralidades, que se consolidam na formação da própria identidade.

Desse modo, ao trazer as falas das estudantes, obtendo um olhar para as vivências das sujeitas, deu-se uma visibilidade para os processos constituidores de identidades ISSN: 2175-0742 | v. 22 | n. 39 | p. 107-123 | Jan. / Jun. 2020 
relacionados às questões de gênero, raça, etnia, classe social e escolarização, demonstrando que as alunas podem receber sentidos e significados em suas vozes. Percebeu-se, também que, o contexto de luta dessas estudantes era diário, não só pelas questões já apresentadas, mas por serem originárias do Nordeste, e estarem vivendo no Sul do Brasil, conservador e preconceituoso.

Os dispositivos que envolvem as práticas escolares contribuíram para que as alunas fortalecessem os processos e se sentissem pertencentes àquele espaço educativo. Torná-las sujeitas visíveis e percebidas é uma forma de mostrar que a escola pode ser um espaço de empoderamento feminino. Constata-se que o empoderamento é uma ação individual e interna. Não se ensina a empoderar-se, mas, ao trabalhar nas atividades educativas com a perspectiva da autora Carolina Maria de Jesus, a professora proporcionou relações sociais e pessoais mais participativas e inclusivas, favorecendo o empoderamento das estudantes. Os espaços de debates sobre as diversas faces das violências de gênero e raça contribuíram para um espaço acolhedor, em que a relação da professora com as alunas fosse transposta em afetividades. "Pode-se afirmar com isso que, atualmente, a EJA tem sido para muitas mulheres uma possibilidade de conquista de autonomia e emancipação e, do mesmo modo, um caminho para a construção de uma sociedade justa [...]” (POGGIO, 2012, p. 95).

O conhecimento é a peça fundamental na sociedade moderna e a EJA é "o conjunto de aprendizagens formais ou não formais dos indivíduos que enriquecem seus conhecimentos e habilita suas competências a fim de atender suas necessidades em função que a sociedade lhe impõe". (ARROYO, 2003, p. 12). Sugere-se, assim, uma proposta pedagógica que atue com o acolhimento e com a afetividade entre as pessoas, valorizando os sujeitos e as sujeitas da EJA, os seus conhecimentos prévios e a sua cultura, contextualizando o que trazem em seus relatos, na busca de quebrar com as relações desiguais entre gênero, raça e classe social.

\section{Referências}

ARROYO, Miguel Gonzalez. Políticas educacionais e desigualdades: à procura de novos significados. Educação e Sociedade, Campinas, v. 31, n. 113, 2010.

ARROYO, Miguel Gonzalez. Educação de jovens-adultos: um campo de direitos e de responsabilidade pública. In: SOARES, Leôncio; GIOVANETTI, Maria Amélia Gomes de Castro; GOMES, Nilma Lino (org.). Diálogos na educação de jovens e adultos. Belo Horizonte: Autêntica, 2005.

ARROYO, Miguel Gonzalez. Pedagogias em Movimento - o que temos a aprender dos Movimentos Sociais? Currículo sem Fronteiras, Belo Horizonte, v. 3, n. 1, p. 28-49, jan./jun. 2003.

BARDIN, Laurence. Análise de conteúdo. Lisboa: Edições 70, 2009. 
BUTLER, Judith. Problema de Gênero: feminismos e subversão da identidade. Rio de Janeiro: Civilização Brasileira, 2013.

CRENSHAW, Kimberle. Documento para encontro de especialistas em aspectos da discriminação racial relativos ao gênero. Revista de Estudos Feministas, Florianópolis, v. 10, n. 1, p. 171-188, jan. 2002.

FRANCO, Maria Laura Puglisi Barbosa. Análise de Conteúdo. Brasília: Líber Livro, 2008.

GOMES, Nilma Lino. Educação de Jovens e Adultos e questão racial: algumas reflexões iniciais. In: SOARES, Leôncio, et al. (org.). Diálogos na educação de jovens e adultos. Belo Horizonte: Autêntica, 2005, p. 87-104.

IBGE - Instituto Brasileiro de Geografia e Estatística. Manual do recenseador. Censo 2010. Rio de Janeiro: IBGE, 2010. [Publicado em 2014].

IBGE - Instituto Brasileiro de Geografia e Estatística. Pesquisa Mensal de Emprego. 2. ed. Rio de Janeiro: IBGE, 2007. (Série Relatórios Metodológicos, v. 23).

JESUS, Carolina Maria de. Quarto de despejo: diário de uma favelada. 10. ed. São Paulo: Ática, 2014.

LOURO, Guacira Lopes. Gênero, sexualidade e educação: uma perspectiva pós estruturalista. Petrópolis, RJ: Vozes, 1997.

MUNANGA, Kabengele. Apresentação. In: MUNANGA, Kabengele (org.). Superando o Racismo na escola. 2. ed. rev. Brasília: Ministério da Educação, Secretaria de Educação Continuada, Alfabetização e Diversidade, 2005. p. 15-20.

MUNANGA, Kabengele. A difícil tarefa de definir quem é negro no Brasil. Estudos avançados [online], São Paulo, v. 18, n. 50, p. 51-66, abr. 2004.

MUNANGA, Kabengele. Negritude: usos e sentidos. São Paulo: Ática, 1988.

PASSOS, Joana Célia dos. As desigualdades educacionais, a população negra e a Educação de Jovens e Adultos. In: LAFFIN, Maria Hermínia Lage Fernandes (org.). Educação de jovens e adultos, diversidade e o mundo do trabalho. Ijuí: Ed. Unijuí, 2012, p. 103-160.

PETRUCCELLI, José. Luís. A cor denominada. Rio de Janeiro: Instituto Brasileiro de Geografia e Estatística, 2000.

POGGIO, Inês Soares Nunes. A construção das relações de gênero. In: LAFFIN, Maria Hermínia Lage Fernandes (org.). Educação de jovens e adultos, diversidade e o mundo do trabalho. Ijuí: Ed. Unijuí, 2012. p. 88-101.

SAFFIOTI, Heleieth. A mulher na sociedade de classes: mito e realidade. São Paulo: Expressão Popular, 2013.

SAFFIOTI, Heleieth. O poder do macho. São Paulo: Moderna, 1987.

SCOTT, Joan W. Gênero: uma categoria útil de análise histórica. Educação \& Realidade, Porto Alegre, v. 20, n. 2, p. 71-100, jul./dez. 1995.

VALLE, Ione Ribeiro. Da "identidade vocacional" a "identidade profissional": a constituição de um corpo docente unificado. Perspectiva, Florianópolis, v. 20, n. especial, p. 209-230, jul./dez. 2002. 
TONELI, Maria Juracy Filgueiras. Sexualidade, gênero e gerações: continuando o debate. In: JACÓ-VILELA, Ana Maria; SATO, Leny (org.). Diálogos em psicologia social. Rio de Janeiro: Centro Edelstein de Pesquisas Sociais, 2012, p. 147-167. ISBN: 978-85-7982-060-1 versão online. Disponível em: http://books.scielo.org/id/vfgfh/pdf/jaco-978857982060112.pdf. Acesso em: 26 maio 2020. 